\title{
The Construction of Electronic Examination for the Course of Information Crime and Computer Forensics
}

\author{
Ling Tang \\ Dept. Information Science and Technology \\ College of Criminal Justice \\ East China University of Political Science and Law \\ Shanghai, China \\ E-mail: ausflug163@163.com
}

\begin{abstract}
During 2018, a course in ECUPL named as Information Crime and Computer Forensics was honored as the excellent course in universities by Shanghai Municipal Education Commission. Thus, it is necessary to make some innovation in curriculum teaching. The teacher decides to set a new project to change the traditional examination into electronic examination to improve efficiency. The electronic examination can generate big data; it will help the teacher to analyze the teaching achievements. In the second half of the 2018, the project was supported by Examination Innovation of Undergraduate Courses for ECUPL.
\end{abstract}

Keywords-course; electronic examination; innovation; education

\section{INTRODUCTION}

In the recent years, human life is inseparable from the Internet. At the same time, information security and cyber-crime are serious problems along with Internet Life. Since 2005, East China University of Political Science and Law (ECUPL for short) has begun to research the task. During the research of 14 years, the teachers in ECUPL have set up a university course with the name information crime and computer forensics. In 2007, the author began to research the problem and teach the course. Up to 2019, a lot of projects such as national important research project have been accomplished. The author is not only the first lecturer of information crime and computer forensics, buts also is chief editor of the new edition of the teaching material. The author has taught the university class for 12 years, nearly 2000 students have studied the course. The students are from all the schools of ECUPL, and their specialties are computer science, the science of law, social science and business etc.

\section{AN EXACT DEFINITION OF COMPUTER FORENSICS}

At the early stage, an expert named as Judd Robbins has carried out the view that computer forensics is in view of the investigation and the analysis techniques which are applied to the potential, legal effect evidence. However, SANS (a famous computer forensics company) considers that computer forensics is some kind of software and appliance. In the light of several pre-defined procedures, some comprehensive examination of computers and related systems, can extract and guard the evidence of computer crime [1].
In China, the definition of computer forensics is follows: the computer forensics refers to that evidence which can be accepted by the court. It is sufficiently reliable and persuasive which resides in computer, network and related peripherals device. Meanwhile, there are other definitions which think that computer forensics is a process that can confirm, guard, extract and file electronic evidence. And all these evidence reside in computer, network and other related equipment, and they can be acceptable and reliable by the law. [2]

\section{DEVELOPMENT OF THE COURSE}

From a worldwide perspective, information Crime and Computer Forensics is a new subject in University. Initially, it was named as computer forensics. It was considered as a complementarity to computer science specialty. With the information security problems has becoming more and more serious, some universities have started to put up some special computer forensics subjects, and some teachers have begun to establish some related courses? In the meantime, some research institutions joined in this area. For example, the Canterbury Christ Church University in the U.K. has put up the subject in Forensic Computing for Master's stage [4]. Every important aspect of digital forensic examination is mixed together, so that it can support criminal investigation along with digital evidence. The subject includes the practical training and the related theory. Therefore, the subject is fit for those students who are already engaged in law science, police enforcement and some related areas. In America, California University has set up the center of security information system which can supply some related courses for the Master's stage. And even a lab has set up to research the problem of computer security and some other area.

From the above, we can draw the collusion that all those organization set up the subject only for master students and for auxiliary section research. There is not a course which sets up for undergraduate students. It is a loss for the college students. This solution is not good for the information crime and computer forensics.

In China, computer forensics course are mostly carried out for the related police universities. None of the regular 
universities has started to research the subject and to teach the undergraduate students.

\section{A. The subject in ECUPL}

The ECUPL is a University for nearly seventy years. It is one of the top legal universities in China. So there is no doubt that the university has a strong legal background. Therefore, the teachers combine computer science and law science together and set up a course called information crime and computer forensics for the undergraduate students in ECUPL. It is popular with students.

To be specific, the course is carried out by the teachers in Department of information science and technology. This department is belonging to Criminalistics law School. The Criminalistics School is good at forensic education and research. An appraisal institution is attached to the school for nearly thirty years. It is an ideal place for the practice of the students whom study this course. Therefore, on account of all these organization above, the course with name as information crime and computer forensics has been a core course with professional characteristics. It mixed with computer science, law science and information security, and it is fit for the aim of cultivating compound applied students. [5]

In 2003, the teachers began to do some related investigation and research work for information crime and computer forensics. After two-years' investigation and design, the department has prepared to set up the course. Eventually, the course was carried out in 2007. So far, twelve grades of students in the Department have been taught. More than 1000 students in other schools of ECUPL have studied the course. So the author gets a lot of teaching experience. In 2013 the course has been the important course in Shanghai honored by Shanghai education department. In 2015, the course was successful accepted by Shanghai Municipal Education Commission. In 2018, the course with the name Information Crime and Computer Forensics has been an excellent course in universities. It is honored by Shanghai Municipal Education Commission. In 2019, the course is honored as the excellent online courses in ECUPL. In the near future, the course will be found on Internet.

In 2005, the course was set up with three credits. There were only 54 lessons including the experiment part. However, after two-year' teaching time, the teachers discovered that the lessons are too short, it is not enough for the teaching. So the teaching plan was optimized. The course is added to four credits. That is to say there are 72 lessons. So the teachers can teach the course $\mathrm{t}$ for 2 times every week. And the experimental class is added to 18 lessons. It occupies 25\% of the total lessons. So the students can have sufficient time to practice and improve their creation ability.

\section{$B$. The character of the course}

With the formulation and implementation of the "Internet Plus" action plan, China made 2025, the action plan for promoting the development of big data, the national cyber security strategy and the new generation of AI development planning, the development and research of information crime and computer forensics has become more and more important.
So that the course is committed to research the problem of network and information security. It is urgent and necessary to research and build the network space security defense system with independent intellectual property rights. This requires not only advanced computer science and network technology, but also some law science and some related management. It is the duty and character of the course to teach and to train some high-level compound application-oriented students. They can get the advanced computer science theory and practical ability, legal knowledge and even certain management quality together. Therefore, the course closely fits for the national strategic needs, and provides the guarantee for students' employment.

This kind of the course requires a high demand for practical ability[6]. Thus, for the practical teaching part, this course arranges a number of related experiments according to the outline of the course. In order to cooperate with the theory of "before, during and after" in information crime and computer forensics, the author has designed several experiments, such as information security experiment, electronic data recovery experiment, computer forensics experiment and a comprehensive training project.

All in all, the whole structure of the course is complete and innovative. It integrates information security, information crime, and computer forensics together. It is helpful for students to understand and grasp the system of cyber security and computer forensics.

\section{The teaching material writen by the teaching team}

The teachers of the course attach great importance to the construction of the teaching materials. The research on information crime and computer forensics has become a new hotspot all over the world, but there is a lack of corresponding textbooks and experimental training books. So the teachers of this course set up a team to accumulate some related resources. In 2010, the teaching material named as Information Crime and Computer Forensics was first compiled and published in China. It has won the second prize of Excellent Textbook Award of Shanghai Colleges and Universities in 2011 in Shanghai. It has also won the first prize of Excellent Textbook Award of ECUPL in 2011.

In order to adapt to the changes and innovation of information crime and computer forensics, with the construction of municipal-level high-quality courses in Shanghai universities, and on the basis of the previous published textbooks, the teachers begun to revised and compiled new edition of Information Crime and Computer Forensics in 2016.And its supporting experimental textbook named as Information Crime and Computer Forensics Training Course (a set of two editions) will be Published by People's Posts and Telecommunications Publishing House.

In 2018, the plan is completed. The new edition of the teaching material named as Information Crime and Computer Forensics is published by the People's Posts and Telecommunications Publishing House. The author has become the editor in chief. It is the painstaking effort of the author's work for 11 years.

In 2019, the matched experimental textbook will be published by the People's Posts and Telecommunications 
Publishing House. The editor is also the member of the teaching team. The book will help the teacher and the students to conduct experiments. Thus, the two books will be the systematic teaching materials for all university students. They will receive an award without doubt.

According to incomplete statistics, this set of teaching materials has been used in East China University of Political Science and Law, Chongqing University of Posts and Telecommunications, Nanjing University of Posts and Telecommunications, Donghua University, Shanxi Police College, Jiangxi Police College, Central Judicial Police College, Sichuan Judicial Police Officer Vocational College and other universities .

\section{The achievement of the teachers and students}

The teaching team attaches great importance to the training of young teachers. They are encouraged to participate in the Shanghai Young Teachers 'Teaching Competition. So that the teaching level and quality of the course can be continuously improved. There are four teachers have successively won the third prize and the winning prize in the first, second and third Shanghai Young Teachers 'Teaching Competition. In recent years, the teachers have gained eight national or project projects and more than ten provincial or ministerial projects. There are more than 20 projects of curriculum construction and teaching reform at all levels, more than 80 academic and teaching research papers, and edited or co-edited more than 30 textbooks (books) are published.

In 2015, three students joined the $1^{\text {st }}$ National Electronic Data Forensics Competition, and won the third prize of person and team.

In 2016, the students also joined some related competitions for national students. They eon the third prize[7].

In 2018, the students joined the MeiYa Cup for National Electronic Data Forensics Competition. They got the second prize.

In 2019, the students joined the Tiger and Whale Cup for National College Students Electronic Data Forensics Competition. They won the Best Organizational Award

\section{THE ELECTRONIC EXAMINATION INNOVATION}

In 2018, after the course has become an excellent course in universities of Shanghai. The author decides to make some progress for the course. So the author sets a new project to change the traditional examination into electronic examination. It is gratified that the project is supported by Examination Innovation of Undergraduate Courses for ECUPL in the same year. It is an innovation for the examination method in the university.

The electronic examination has been devoted to innovate the teaching method of the course. With the development of computer technology, network and computer have been an important part of the course. So the author decides to innovate the traditional examination forms in the university.

In the electronic examination, the examination questions are divided into seven types: single choice questions, multiple choice questions, blank filling questions, judgments questions, short answer questions, discussion questions and case questions The number of questions can meet the need of the innovation project. At the same time, the teacher has accumulated a lot of the questions. So that the teacher can form a variety of content and abundant examination questions, which lays a good foundation for the construction of the question bank.

As to the design of test questions, the author can cover a wide range of the theory, and focus on prominent, reasonable difficulty, so that the innovation can comprehensively examine the students 'knowledge accumulation and problem-solving ability. Examination questions include objective questions such as choice questions, and subjective questions such as short answers and exposition questions. The objective questions focus on students 'grasp of basic knowledge, while the subjective questions focus on students' ability to analyze and understand important issues, to understand and analyze relevant cases, to organize relevant materials and to design systems. The scoring criteria are objective and reasonable, which can fairly evaluate the examinee's exam situation in order to truly reflect the students 'academic level [8].

By using the electronic examination system, the teacher can review papers efficiently and quickly. And the system will improve the correctness of marking test papers. The system can not only further enhance the construction of the examination questions bank, can but also make the examination papers present basic, rational and innovative characteristics. It can further and accurately check the actual level of students and their ability to solve problems. It has senior credibility, effectiveness and distinction. It has great guiding significance for future teaching work and personnel training.

It will improve the teaching quality. Traditional classroom teaching and cyber exams are combined together, so that the teacher can keep pace with the times. It can not only make the teaching and exam methods more vividly, but also increase the flexibility and interesting of the course [9].

As to the teaching effectiveness. The innovation can strengthen students' understanding and digestion of the professional theory and technology in class. And the results of the exams are easily and accurately got by the computer. The electronic examination will establish a set of scientific and perfect evaluation system and evaluation mechanism. This can not only test the knowledge learnt by students in class, but also cultivate students 'innovative consciousness and ability to solve practical problems. It will further enhance the connotation construction of this subject, and achieve the goal of training compound applied talents integrating theory with practice.

\section{THE ELECTRONIC EXAMINATION INNOVATION WITH BIG DATA}

Big data refers to these data that cannot be captured, managed and processed by conventional software tools. It requires new processing modes, so that people can hold with strong decision-making power, insight and process optimization capabilities. It is necessary for the teachers to adapt to massive, high growth rate and diversified information assets. That is to say, the final goal of the electronic examination innovation is to analyze the students' score with 
bid data, and then optimize the question bank with big data. At last, the teacher even can anticipate the students 'score and mastery of knowledge.

Big data is a comprehensive subject based on computer science, mining algorithm as the core. It is even closely oriented to industry applications. Its main technology involves with probability theory, non-mathematical statistics, data mining, algorithm non-data structure, computer network gorgeous, parallel computing and other fields, so that the subject owns the highest professional requirements for the laboratory in universities. The laboratories should also provide a basic open environment, as well as a computing environment for big data and practical big data cases for electronic examination innovation. The preparation of these experimental materials should meet the demand of professional big data laboratory.

According to the needs of the electronic examination innovation project, the laboratory construction of big data should embody the overall image of "modern, elegant, beautiful and applicable". During the construction of the project, teachers should pay more attention to the construction of the distribution system, lightning protection and grounding system, integrated wiring system and air conditioning system in the classroom, so that it can ensure the normal operation of the electronic examination innovation system.

\section{THE IDEAS FOR THE FUTURE WORK}

With the development of computer technology, new research points come out endlessly. So the teacher has to keep on developing. So the author needs to improve the teaching work, surmise and optimize the experience of electronic examination innovation, and enlarge the current teaching achievement, improve the quality of teaching. The course is taught by the teaching team in universities. So the teachers need constant retraining.

The teachers should keep on join in the training class to improve themselves. Pay close attention to the latest development of this discipline, make it useful in the teaching process. So the students can grasp the latest developments.

The teachers should insist on the idea that teaching in class does not simply mean imparting what is written in the book .It is also very important to train their capability to gain knowledge by themselves, to inspire the their capability to discover new fields. In order to train their innovation capability, about 4 students constitute several research teams voluntarily. They are asked to do some research of information crime or computer forensics. The subject is chosen by themselves. At the end of the semester, each team should stand on the podium and demonstrate their research results. Their performance will infect their final scores.

The teachers use more flexible and more multiform way to examine the students. The aim of the exam is not for score but for the students to grasp the knowledge and comprehend the progress of the discipline, so that they can improve the creativity and research capability.

The teachers should focus on AI issue. As above-mentioned, nowadays, big data is an impaotant part of the innovation work .If the author combined the AI with big data ,it can improve the efficiency of big data and electronic device. It is beyond any doubt that it will become a new direction for information crime and computer forensics.

With the help of cyber work, the teacher sets up the online class through Internet. The students can communicate with the teacher after class; it is a very useful complement to the rational teaching method.

\section{CONCLUSIONS}

In this article, the author introduces the current achievement of information crime and computer forensics.

Based on this, the author put forward the idea of electronic examination. It is an innovation about the examination of the course. By using big data, the teacher should analysis and mastery of students' learning situation. In the future, the electronic examination innovation system can improve the quality of teaching and cultivate excellent students.

In 2019, the course is honored as the excellent online courses in ECUPL. Hence, the author will committed to optimizing the course and put the online resource in the future. The students all over the world can learn the subject from Internet.

\section{ACKNOWLEDGMENT}

This work is supported by Excellent Courses of Shanghai Education Municipal Commission for Universities in 2018. This work is supported by 2018 Curriculum Examination Innovation Project of ECUPL (A-0312-18-16917).

\section{REFERENCES}

[1] Robbins, Judd. "An Explanation of Computer Forensics." URL: http://www.computerforensics.net/forensics.htm.

[2] Chen Long, Mai Yong Hao, Huang Chuan He , The Technology of Computer Forensics,Wuhan University Publishing house,2007, pp.1-10. (In Chinese)

[3] Peter Sommer: “Computer Forensics: an Introduction”URL: http://www.virtualcity.co.uk/vcaforens.htm

[4] URL: http://www.canterbury.ac.uk/studyhere/HomeNew.aspx

[5] Dang En Hong, the Analssis of computer forensics.China Water Transport.vol08,2007 (In Chinese)

[6] Song Xiuli, Chen Long, Deng HongYao.The discovery of computer foensics experiments teahing, vol26(16,2007) (In Chinese)

[7] URL:http://www.ecupl.edu.cn

[8] Cheng Ziao, Zhao Yue, Meng Bo, A New Computer Examination System Based on Network, Electronic Technology and Software Engineering Collection, 2018, 01 (In Chinese)

[9] Wu sun Dong, The Establishment and Implementation of Paperless Examination LAN, lectronic Technology and Software Engineering Collection, 2018, 06. (In Chinese) 